\title{
Eccentric training for shoulder abductors improves pain, function and isokinetic performance in subjects with shoulder impingement syndrome - a case series
}

Treino excêntrico para abdutores do ombro melhora dor, função e desempenho isocinético em sujeitos com síndrome do impacto - série de casos

Paula R. Camargo 1,2, Mariana A. Avila², Francisco Alburquerque-Sendín ${ }^{3}$, Naoe A. Asso², Larissa H. Hashimoto², Tania F. Salvini²

\begin{abstract}
Background: Conservative treatments have been proposed for people with shoulder impingement syndrome (SIS), such as strengthening of the rotator cuff and scapular muscles and stretching of the soft tissues of the shoulder. However, there is a lack of studies analyzing the effectiveness of eccentric training in the treatment of SIS. Objectives: To evaluate the effects of eccentric training for shoulder abductors on pain, function, and isokinetic performance during concentric and eccentric abduction of the shoulder in subjects with SIS. Methods: Twenty subjects (7 females, 34.2 SD 10.2 years, 1.7 SD $0.1 \mathrm{~m}, 78.0$ SD $16.3 \mathrm{~kg}$ ) with unilateral SIS completed the study protocol. Bilateral isokinetic eccentric training at $60 \%$ for shoulder abductors was performed for six consecutive weeks, twice a week, on alternate days. For each training day, three sets of 10 repetitions were performed with a 3-minute rest period between the sets for each side. The range of motion trained was $60^{\circ}$ (ranging from $80^{\circ}$ to $20^{\circ}$ ). The Disabilities of the Arm, Shoulder and Hand (DASH) questionnaire was used to evaluate functional status and symptoms of the upper limbs. Peak torque, total work and acceleration time were measured during concentric and eccentric abduction of the arm at $60 \%$ and $180 \%$ s using an isokinetic dynamometer. Results: DASH scores, peak torque, total work and acceleration time improved $(p<0.05)$ after the period of intervention. Conclusions: This study suggests that isokinetic eccentric training for shoulder abductors improves physical function of the upper limbs in subjects with SIS. Article registered in Clinicaltrials.gov under number NCT01090271.
\end{abstract}

Keywords: physical therapy; supraspinatus; subacromial; DASH.

\begin{abstract}
Resumo
Contextualização: Tratamentos conservadores têm sido propostos para pessoas com síndrome do impacto (SI) do ombro, como fortalecimento do manguito rotador e dos músculos escapulares e alongamento dos tecidos moles do ombro. No entanto, são escassos os estudos que analisaram a eficácia do treinamento excêntrico no tratamento da SI. Objetivos: Avaliar os efeitos do treinamento excêntrico para abdutores do ombro na dor, função e desempenho isocinético durante a abdução concêntrica e excêntrica do ombro em indivíduos com SI. Métodos: Vinte indivíduos (sete mulheres, 34,2 DP 10,2 anos, 1,7 DP 0,1 m, 78,0 DP 16,3 kg) com SI unilateral completaram o protocolo do estudo. Realizou-se treinamento isocinético excêntrico bilateral a $60 \% \mathrm{~s}$ para abdutores do ombro durante seis semanas consecutivas, duas vezes por semana, em dias alternados. Para cada dia de treinamento, foram realizadas três séries de dez repetições, com um período de descanso de 3 minutos entre as séries para cada lado. A amplitude de movimento treinada foi de $60^{\circ}\left(\right.$ de $80^{\circ}$ a $\left.20^{\circ}\right)$. $O$ questionário Disabilities of the Arm, Shoulder and Hand (DASH) foi utilizado para avaliar a função e os sintomas dos membros superiores. O pico de torque, o trabalho total e o tempo de aceleração foram avaliados durante a abdução concêntrica e excêntrica do braço a $60 \%$ s e 180\% por meio de um dinamômetro isocinético. Resultados: As pontuações do DASH, o pico de torque, o trabalho total e o tempo de aceleração melhoraram $(p<0,05)$ após o período de intervenção. Conclusões: Este estudo sugere que o treinamento isocinético excêntrico para abdutores do ombro melhora a função física dos membros superiores em indivíduos com SI. Artigo registrado no Clinicaltrials. gov sob o número NCT01090271.
\end{abstract}

Palavras-chave: fisioterapia; supraespinal; subacromial; DASH.

Received: 09/26/2011 - Revised: 09/28/2011 - Accepted: 09/30/2011

Physical Therapy Graduation Program, Universidade Metodista de Piracicaba (UNIMEP), Piracicaba, SP, Brazi

${ }^{2}$ Physical Therapy Department, Universidade Federal de São Carlos (UFSCar), São Carlos, SP, Brazil

${ }^{3}$ Physical Therapy Department, University of Salamanca, Salamanca, Spain

Correspondence to: Paula Rezende Camargo, Mestrado em Fisioterapia, Universidade Metodista de Piracicaba, Rodovia do Açúcar, km 156, CEP: 13400-901, Piracicaba, SP, Brasil,

e-mail: paularezendecamargo@gmail.com 


\section{Introduction $: \therefore$.}

Shoulder impingement syndrome (SIS) is one of the most common causes of shoulder pain ${ }^{1}$. The pain occurs because of compression and mechanical abrasion of the subacromial structures against the anterior undersurface of the acromion and coracoacromial ligament, especially during elevation of the $\mathrm{arm}^{2}$. The supraspinatus tendon is usually the most affected structure due to its location just under the coracoacromial ligament ${ }^{3}$. Apoptosis in this tendon has already been described in subjects who were treated with subacromial decompression ${ }^{4}$.

Conservative treatments have been proposed for people with SIS $^{5-9}$. The literature supports the strengthening of the rotator cuff and scapular muscles and the stretching of the soft tissue of the shoulder ${ }^{6,9,10}$. Good clinical results of eccentric training for the supraspinatus and deltoid muscles ${ }^{11}$ and for the rotator cuff ${ }^{12}$ were demonstrated in subjects with painful SIS. Other studies have also shown successful results with eccentric training in different types of tendinopathies ${ }^{13-16}$.

Eccentric training is very efficient for muscular and tendon strengthening ${ }^{17,18}$. Also, this type of training may induce remodeling of the tendon ${ }^{18}$ and changes in neovessels ${ }^{19}$. Although the studies related to eccentric training in subjects with SIS have shown interesting results, more investigations are warranted to evaluate the effectiveness of eccentric training in the treatment of SIS.

The aim of this study was to evaluate the effects of eccentric training for shoulder abductors on pain, physical functional status and isokinetic performance during concentric and eccentric abduction of the shoulder in subjects with SIS. It was hypothesized that eccentric training for shoulder abductors would improve pain, function and isokinetic parameters in these subjects.

\section{Methods : :}

\section{Participants}

The participants of this study were recruited from a physical therapy waiting list at the clinic at the Universidade Federal de São Carlos (UFSCar), São Carlos, SP, Brazil and also from flyer advertisements at the University premises and orthopedic clinics. The participants with shoulder pain were first evaluated and diagnosed with SIS by a physical therapist and then the diagnosis was confirmed by an orthopedic physician. The clinical diagnosis of SIS was made following the clinical criteria of reproduction of pain by at least 3 of the tests: Neer ${ }^{2}$, Hawkins ${ }^{20}$, Jobe ${ }^{21}$, Speed ${ }^{22}$ and Gerber ${ }^{23}$. They also had to present painful range of motion during active shoulder elevation. Ultrasonography for both shoulders was performed by an experienced radiologist and used to check tendinopathy of supraspinatus and rule out progression of impingement to rotator cuff or long head biceps tears. Ultrasonography improves the differential diagnosis for shoulder pain as it has high sensitivity (98.1\%) for identifying rotator cuff tears ${ }^{24}$. Other studies also used ultrasonography in the evaluation of patients with SIS ${ }^{6,11,25}$.

Exclusion criteria included pregnancy, torn rotator cuff or long head biceps tendons, ligamentous laxity based on positive Sulcus test ${ }^{26}$ or a positive Apprehension test ${ }^{27,28}$, previous shoulder or neck surgery, hooked acromion, systemic illnesses, corticosteroid injection 3 months prior to evaluation, and physical therapy treatment 6 months prior to evaluation.

Thirty-seven participants (22 males) with shoulder pain were initially recruited and evaluated. Twelve of them did not meet the inclusion criteria. From the remaining 25 participants, five did not complete the period of the study because of work scheduling or personal problems. Therefore, 20 participants (7 women, 34.2 SD 10.2 years (range 20-51 years), 1.7 SD $0.1 \mathrm{~m}$ (range 1.60-1.96 m), $78.0 \mathrm{SD} 16.3 \mathrm{~kg}$ (range $55-120 \mathrm{~kg}$, body mass index $25.87 \mathrm{SD} 3.29 \mathrm{~kg} / \mathrm{m}^{2}$ (range $20.38-31.24 \mathrm{~kg} / \mathrm{m}^{2}$ )) with unilateral SIS completed the study. The duration of their shoulder pain was $2.8 \mathrm{SD}$ 2.9 years (range from 5 to 120 months) based on self-report. All participants were still able to work and perform their daily activities despite of pain. None of them was on sick leave. The involved side was the dominant side for 12 participants.

All participants gave their written informed consent to participate in this study, which was approved by the local Ethical Committee of the UFSCar (Approval 214/2007) and conducted according to the Helsinki Statement. This study was registered on Clinicaltrials.gov (NCT01090271).

\section{Evaluations}

Two baseline evaluations (evaluation 1 and evaluation 2) were performed before the start of the intervention with a period of 4 weeks between them, and 2 follow-up evaluations were performed immediately after 6 weeks of intervention (evaluation 3) and after 6 weeks after the end of the intervention period (evaluation 4). Two baseline evaluations were used to assess any possible improvement without intervention. 


\section{The Disabilities of the Arm, Shoulder, and Hand (DASH) questionnaire}

The DASH self-report questionnaire was used to evaluate functional status and symptoms of the upper limbs of the subjects. The maximum score of the questionnaire is 100 , which indicates the worst possible condition ${ }^{29}$. This questionnaire was previously used to assess the effectiveness of an intervention program in subjects with SIS $^{6,30}$ and has been shown to be a reliable, valid and responsive measure ${ }^{31,32}$.

\section{Isokinetic evaluation}

Involved and uninvolved sides were randomly chosen to begin the evaluation. As studies have shown bilateral deficits in people with unilateral SIS ${ }^{33-35}$, both sides were evaluated and trained. Peak torque, total work and acceleration time were measured during concentric and eccentric abduction of the arm using an isokinetic dynamometer (Biodex Multi-Joint System 3, Biodex Medical System Inc., NY, USA). Peak torque was defined as the mean of the maximum torque produced during the 5 repetitions. Total work was determined by the sum of work for every repetition performed in the set. Acceleration time was described as the total time used to reach the preset dynamometer speed.

Participants performed a warm-up procedure at the beginning of the testing sessions that consisted of shoulder movements in all directions followed by stretching exercises for the upper trapezius (3 repetitions of 30s), as previously proposed ${ }^{33}$. Afterwards, the participants were seated and their trunk was stabilized with diagonal and pelvic straps. The arm was positioned in the scapular plane, neutral rotation and $20^{\circ}$ abduction with the elbow in full extension. The acromioclavicular joint was aligned over the rotational machine axis. Previous studies have used this positioning to test the subjects during isokinetic abduction $^{25,33}$. Although studies recommend abduction with glenohumeral internal rotation (empty can) to better activate the supraspinatus ${ }^{3,36}$, we performed a pilot study where the participants were not able to perform abduction with internal rotation without increasing pain; therefore, neutral rotation was used for evaluations and intervention. Gravity correction was performed with the arm relaxed in $80^{\circ}$ of abduction. The total range of motion assessed was $60^{\circ}$. This range of motion was chosen to avoid pain and exacerbation of impingement in $90^{\circ}$ of elevation ${ }^{37}$.

The evaluation protocol consisted of concentric and eccentric abduction at $60^{\circ} / \mathrm{s}$ and $180^{\circ} / \mathrm{s}$. After some procedure explanations, the participants were familiarized with the procedure by performing 3 submaximal repetitions at each speed.
A 2-minute rest period was provided between familiarization and testing. The isokinetic evaluation at each speed consisted of 5 repetitions of maximal effort during the movements. The isokinetic evaluations started at $60^{\circ} / \mathrm{s}$. A 2-minute rest period was given between each speed. A standardized verbal encouragement to develop maximal strength in all contractions was given by the principal investigator in a consistent manner to all participants during the testing procedure. No participants experienced pain during the test.

\section{Eccentric training}

The positioning for the eccentric training was the same used for the isokinetic evaluation. The eccentric training for the shoulder abductors was performed with maximal strength in all contractions for 6 consecutive weeks, 2 days/ week, on alternate days. Studies have shown positive effects of a twice-week intervention ${ }^{5,6}$. The training was performed bilaterally in the isokinetic dynamometer at $60^{\circ} / \mathrm{s}^{38}$ and the range of motion trained was $60^{\circ}$ (ranging from $80^{\circ}$ to $20^{\circ}$ ). This range of motion was chosen to avoid impingement at $90^{\circ}$ elevation ${ }^{37}$. For each training day, 3 sets of 10 repetitions were performed with a 3-minute rest period between the sets for each side. The same verbal encouragement given in the evaluations was provided during all training sessions. All participants performed only the eccentric training proposed in this study while the duration of the study. No other forms of intervention were provided during this period. Also, no specific warm-up or cool-down exercises were performed in addition to the eccentric training.

\section{Sample size calculation}

The sample size calculation was performed with the software ENE2.0 ${ }^{\odot}$ (GlaxoSmithKline, Universidad Autónoma de Barcelona, Spain). The calculations were based on detecting a maximum effect size of $28.6 \mathrm{msec}$ in the acceleration time between two means, at least, during concentric abduction of the shoulder at $60^{\circ} / \mathrm{s}$ with a standard deviation of $26 \mathrm{msec}^{33}$, an alpha level of 0.05 , and a desired power of $90 \%$. These assumptions generated a sample size of at least 19 subjects. The acceleration time was the variable chosen for the calculation of the sample size as some investigations have demonstrated that SIS does not affect muscle torque of the shoulder ${ }^{39-41}$, but affects scapular and rotator cuff muscle activity in subjects with SIS during arm elevation ${ }^{42-44}$. Therefore, the acceleration time may provide valuable information regarding neuromuscular readiness to produce maximal contraction. 


\section{Statistical analysis}

Statistical analysis was conducted with the SPSS16.0 package (SPSS, Chicago, Il). Mean, standard error and 95\% confidence intervals of the values are presented. The Kolmogorov-Smirnov test showed a normal distribution of quantitative data ( $p>0.05)$. For the DASH questionnaire, a 1-way repeated measures analysis of variance (ANOVA) was used to test the main effect of time (evaluations 1, 2, 3 and 4). For each dependent variable (peak torque, total work and acceleration time), a 4x2 mixed model ANOVA with main effects of time (evaluations 1,2, 3 and 4) as the repeated factor and side (involved and uninvolved) as the independent factor was used at each mode (concentric and eccentric) and speed, separately. Interactions of time and side were also analyzed. The Huynh-Feldt Epsilon correction and the Bonferroni test for post hoc analysis were used when necessary. A p value of less than 0.05 was considered significant.

Effect sizes for each time were calculated using Cohen's $d$ coefficient ${ }^{45}$. An effect size greater than 0.8 was considered large, around 0.5 moderate, and less than 0.2 small. The time periods evaluated were paired as following: evaluation 1 - evaluation 3; evaluation 2 - evaluation 3; evaluation 3 - evaluation 4.

\section{Results $: \therefore$.}

\section{DASH questionnaire}

Statistically significant main effect of time was found for the DASH score $(\mathrm{p}<0.01)$. DASH scores were lower after the period of intervention (Table 1), which lower scores indicate better condition. There was no difference $(\mathrm{p}=0.25)$ between evaluations 1 and 2. However, evaluation 4 showed lower values compared to evaluations $1(\mathrm{p}<0.01), 2(\mathrm{p}=0.02)$ and $3(\mathrm{p}=0.02)$; and evaluation 3 when compared to evaluation 1 ( $p<0.01)$.

A large effect size was found when evaluation 1 was compared to evaluation 3, and a moderate effect size was demonstrated when evaluation 3 was compared to evaluations 2 and 4 (Table 2).

\section{Isokinetic parameters}

Interaction effect of side $x$ time - There were no significant interactions between side and time. Peak torque (concentric$60^{\circ} / \mathrm{s}, \mathrm{p}=0.89$; eccentric $-60^{\circ}, \mathrm{p}=0.80$; concentric $-180^{\circ} / \mathrm{s}, \mathrm{p}=0.97$; eccentric- $180^{\circ} / \mathrm{s}, \mathrm{p}=0.87$ ), total work (concentric- $60^{\circ} / \mathrm{s}, \mathrm{p}=0.91$; eccentric- $60^{\circ}, \mathrm{p}=0.4$; concentric- $180^{\circ} / \mathrm{s}, \mathrm{p}=0.7$; eccentric $-180^{\circ} / \mathrm{s}$, $\mathrm{p}=0.93$ ) and acceleration time (concentric- $60^{\circ} / \mathrm{s}, \mathrm{p}=0.77$; eccentric- $60^{\circ}, \mathrm{p}=0.29$; concentric $-180^{\circ} / \mathrm{s}, \mathrm{p}=0.36$; eccentric- $180^{\circ} / \mathrm{s}$, $\mathrm{p}=0.55$ ) did not identify differences between means (Table 3 ).

Main effect of side - The intra-side analysis, separately, showed few differences along the evaluations. However, those differences were found in the same variables for both sides $(\mathrm{p}<0.05)$ : total work (eccentric $-60^{\circ} / \mathrm{s}$ and $\left.180^{\circ} / \mathrm{s}\right)$, and acceleration time (eccentric-180\%/s). The post-hoc analyses identified a different pattern for pairwise comparisons of each side. In this way, the uninvolved side demonstrated to be more homogeneous in the baseline evaluations (1 and 2), with statistical differences between these evaluations and the post-intervention measures (evaluations 3 and 4). The differences were between evaluations 1 and $3(p=0.01)$, evaluations 1 and $4(\mathrm{p}<0.01)$, and evaluations 2 and $4(\mathrm{p}=0.01)$ for total work (eccentric-60\% $/ \mathrm{s})$; and between evaluations 1 and $3(p=0.01)$, evaluations 1 and $4(p<0.01)$, evaluations 2 and 4 ( $p=0.03$ ) for total work (eccentric- $\left.180^{\circ} / \mathrm{s}\right)$. Finally, the

Table 1. DASH scores for 20 subjects with shoulder impingement syndrome.

\begin{tabular}{|c|c|c|c|c|}
\hline & \multicolumn{2}{|c|}{ Pre-eccentric training } & \multicolumn{2}{|c|}{ Post-eccentric training } \\
\hline & Evaluation 1 & Evaluation 2 & Evaluation 3 & Evaluation 4 \\
\hline DASH score & $18.78 \pm 3.06(20.85 ; 16.72)$ & $14.28 \pm 3.24(16.48 ; 12.09)$ & $9.70 \pm 2.09(11.12 ; 8.29)^{\star \star}$ & $5.49 \pm 1.25(6.34 ; 4.65)^{\star}$ \\
\hline
\end{tabular}

Results are mean \pm standard error ( $95 \%$ confidence interval). ${ }^{\star} p<0.05$ when compared to evaluations 1,2 and $3 ;{ }^{* \star} p<0.05$ when compared to evaluation 1.

Table 2. Effect size for Disabilities of the Arm, Shoulder and Hand (DASH) score in 20 subjects with shoulder impingement syndrome. Evaluations 1 and 2: pre-eccentric training; evaluations 3 and 4: post-eccentric training.

\begin{tabular}{lcc}
\hline & Difference between means & Cohen's $d$ coefficient \\
\hline Evaluation 1 - Evaluation 3 & 9.08 & -0.78 \\
\hline Evaluation 2 - Evaluation 3 & $95 \% \mathrm{Cl}(3.04,15.12)$ & -0.38 \\
\hline Evaluation 3 - Evaluation 4 & 4.58 & -0.56 \\
\hline
\end{tabular}

95\% Cl: confidence interval. 


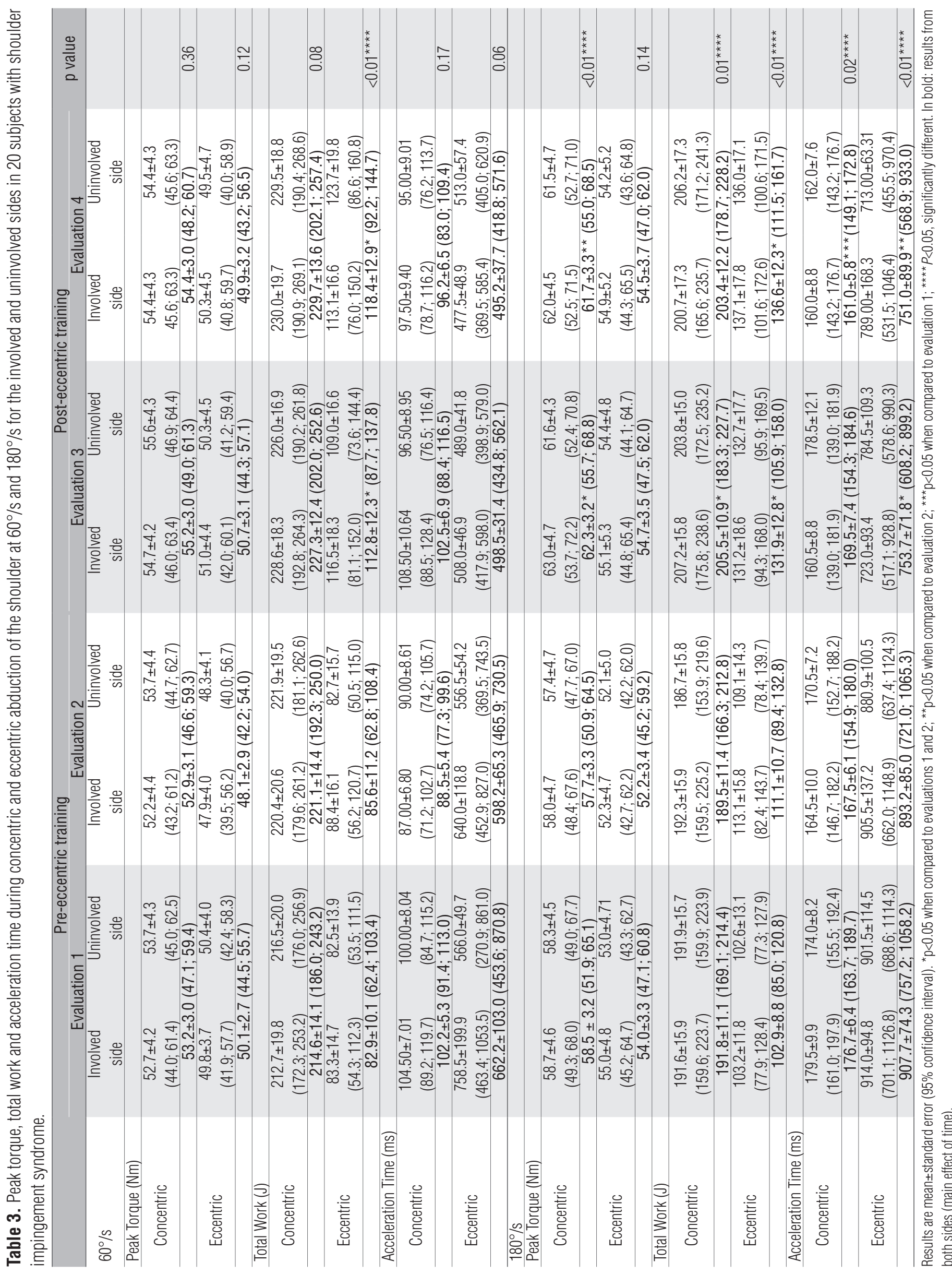


statistical differences for acceleration time (eccentric-180$\circ / \mathrm{s}$ ) were observed between evaluations 2 and 4 ( $\mathrm{p}=0.03$ ). Notably, the involved side showed less pairwise differences and always between evaluation 1 and post-intervention measures. In this case, the differences were between evaluations 1 and $3(\mathrm{p}=0.02)$, evaluations 1 and $4(\mathrm{p}=0.04)$ for total work (eccentric- $60^{\circ} / \mathrm{s}$ ); between evaluations 1 and 3 $(\mathrm{p}=0.04)$, and evaluations 1 and $4(\mathrm{p}=0.01)$ for total work (eccentric-180\%/s), and between evaluations 1 and $3(p=0.01$, Table 3) for acceleration time (eccentric-180\%/s). The effect size for the isokinetic variables for each side was small and moderate for most of the conditions. Table 4 shows the effect size for the variables that reached statistically significance $(\mathrm{p}<0.05)$.

Table 4. Effect size for the isokinetic variables in 20 subjects with shoulder impingement syndrome for each side. Evaluations 1 and 2: pre-eccentric training; evaluations 3 and 4: post-eccentric training.

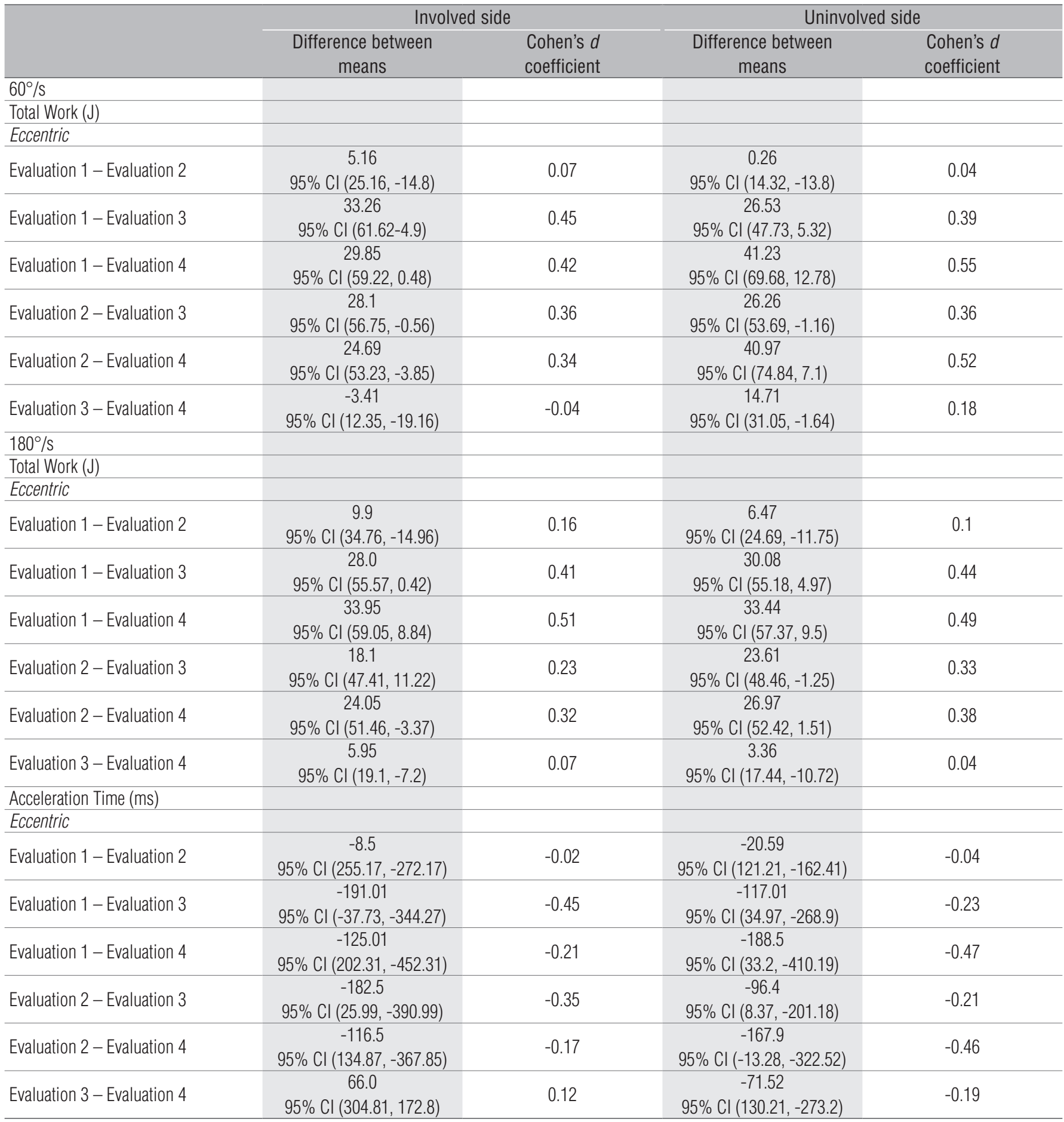

$95 \% \mathrm{Cl}$ : confidence interval. 
Main effect of time Significant main effect of time was found in some conditions after the period of eccentric training, as occurred with peak torque (concentric- $180^{\circ} / \mathrm{s}$ ), total work (concentric$180^{\circ} / \mathrm{s}$; eccentric- $60^{\circ}$ and $180^{\circ} / \mathrm{s}$ ) and acceleration time (concentric- $180^{\circ} / \mathrm{s}$; eccentric- $180^{\circ} / \mathrm{s}$ ) (Table 3). Evaluation 3 improved compared to evaluations 1 and 2 for the following outcomes: peak torque (concentric- $180^{\circ} / \mathrm{s}, \mathrm{p}=0.03$ and $\mathrm{p}=0.01$, respectively), total work (concentric- $180^{\circ} / \mathrm{s}, \mathrm{p}=0.04$ and $\mathrm{p}=0.02$, respectively; eccentric- $60^{\circ}, \mathrm{p}<0.01$, respectively; eccentric- $180^{\circ} / \mathrm{s}, \mathrm{p}<0.01$ and $\mathrm{p}=0.02$ respectively), which the results after the intervention period were higher than before the exercises; and acceleration time (eccentric- $180^{\circ} / \mathrm{s}, \mathrm{p}<0.01$ and $\mathrm{p}=0.01$, respectively) with lower values at the two last evaluations. This tendency was maintained for peak torque (concentric- $180^{\circ} / \mathrm{s}, \mathrm{p}=0.03$ ) and acceleration time (eccentric- $180^{\circ} / \mathrm{s}, \mathrm{p}=0.04$ ) which improved during the follow-up period (evaluation 4) when compared to evaluation 2. Acceleration time (concentric- $180^{\circ} / \mathrm{s}$ ) also improved ( $\mathrm{p}=0.02$ ) during the follow-up period (evaluation 4) when compared to evaluation 1.

Table 5 shows the effect size for the variables that reached statistical significance $(p<0.05)$, which was small for most of the conditions. As observed in the main effect of side and in the interaction effect of side by time there were no differences ( $p>0.05$ ) for the baseline period in all conditions.

\section{Discussion $: \because$.}

This study showed that eccentric training for shoulder abductors could be effective to reduce pain and physical impairment of the upper limbs during daily activities, as well as to improve isokinetic parameters in subjects with SIS. It is important to state that large and moderate within-group effect sizes were only demonstrated for DASH score, while small and moderate within-group effects were observed for the isokinetic variables.

The literature supports the strengthening of the rotator cuff and scapular muscles and the stretching of the soft tissues of the shoulder to reduce pain and functional loss in people with SIS ${ }^{6,9,10}$. Although previous reports also support the idea that elevation exercises should be avoided in SIS $^{8,46}$, a study showed good clinical results of eccentric training for the supraspinatus and deltoid muscles in chronic painful SIS ${ }^{11}$.

Many studies have suggested the use of eccentric exercise in the preventive care or rehabilitation ${ }^{11,13,15,18,47-49}$. Eccentric exercises have also been advocated as efficient in the treatment of several tendon disorders because this type of exercise accelerates tenocytes metabolism and may speed repair ${ }^{18,50}$. Therefore, tendons become stronger as tenoblast activity increases and an appropriate collagen reaction accelerates ${ }^{18}$.
Table 5. Effect size for the isokinetic variables in 20 subjects with shoulder impingement syndrome. Evaluations 1 and 2: pre-eccentric training; evaluations 3 and 4: post-eccentric training.

\begin{tabular}{|c|c|c|}
\hline & $\begin{array}{l}\text { Difference between } \\
\text { means }\end{array}$ & $\begin{array}{l}\text { Cohen's } d \\
\text { coefficient }\end{array}$ \\
\hline \multicolumn{3}{|l|}{$60^{\circ} / \mathrm{s}$} \\
\hline \multicolumn{3}{|l|}{ Total Work (J) } \\
\hline \multicolumn{3}{|l|}{ Eccentric } \\
\hline Evaluation 1 - Evaluation 3 & $\begin{array}{c}29.89 \\
95 \% \mathrm{Cl}(13.14,46.63)\end{array}$ & 0.42 \\
\hline Evaluation 2 - Evaluation 3 & $\begin{array}{c}27.18 \\
95 \% \text { Cl }(8.42,45.93)\end{array}$ & 0.36 \\
\hline Evaluation 3 - Evaluation 4 & $\begin{array}{c}5.65 \\
95 \% \text { Cl }(-5.07,16.37)\end{array}$ & 0.07 \\
\hline \multicolumn{3}{|l|}{$180^{\circ} / \mathrm{s}$} \\
\hline \multicolumn{3}{|l|}{ Peak Torque (Nm) } \\
\hline \multicolumn{3}{|l|}{ Concentric } \\
\hline Evaluation 1 - Evaluation 3 & $\begin{array}{c}3.75 \\
95 \% \mathrm{Cl}(0.27,7.24)\end{array}$ & 0.18 \\
\hline Evaluation 2 - Evaluation 3 & $\begin{array}{c}4.58 \\
95 \% \mathrm{Cl}(1.03,8.13)\end{array}$ & 0.22 \\
\hline Evaluation 3 - Evaluation 4 & $\begin{array}{c}-0.52 \\
95 \% \text { Cl }(-2.39,1.35)\end{array}$ & -0.02 \\
\hline \multicolumn{3}{|l|}{ Total Work (J) } \\
\hline \multicolumn{3}{|l|}{ Concentric } \\
\hline Evaluation 1 - Evaluation 3 & $\begin{array}{c}13.75 \\
95 \% \mathrm{Cl}(0.62,26.89)\end{array}$ & 0.19 \\
\hline Evaluation 2 - Evaluation 3 & $\begin{array}{c}16.00 \\
95 \% \text { Cl }(1.72,30.28)\end{array}$ & 0.22 \\
\hline Evaluation 3 - Evaluation 4 & $\begin{array}{c}-2.07 \\
95 \% \mathrm{Cl}(-15.98,11.82)\end{array}$ & -0.02 \\
\hline \multicolumn{3}{|l|}{ Eccentric } \\
\hline Evaluation 1 - Evaluation 3 & $\begin{array}{c}29.03 \\
95 \% \text { Cl }(11.40,46.66)\end{array}$ & 0.42 \\
\hline Evaluation 2 - Evaluation 3 & $\begin{array}{c}20.85 \\
95 \% \operatorname{Cl}(2.68,39.01)\end{array}$ & 0.28 \\
\hline Evaluation 3 - Evaluation 4 & $\begin{array}{c}4.65 \\
95 \% \text { Cl }(-4.45,13.76)\end{array}$ & 0.05 \\
\hline \multicolumn{3}{|l|}{ Acceleration Time (ms) } \\
\hline \multicolumn{3}{|l|}{ Concentric } \\
\hline Evaluation 1 - Evaluation 3 & $\begin{array}{c}-7.25 \\
95 \% \mathrm{Cl}(-30.21,15.71)\end{array}$ & -0.16 \\
\hline Evaluation 2 - Evaluation 3 & $\begin{array}{c}2.00 \\
95 \% \text { Cl }(-21.17,25.17)\end{array}$ & 0.04 \\
\hline Evaluation 3 - Evaluation 4 & $\begin{array}{c}-8.50 \\
95 \% \mathrm{Cl}(-27.91,10.91)\end{array}$ & -0.20 \\
\hline \multicolumn{3}{|l|}{ Eccentric } \\
\hline Evaluation 1 - Evaluation 3 & $\begin{array}{c}-154.00 \\
95 \% \text { Cl }(-256.03,-51.96)\end{array}$ & -0.33 \\
\hline Evaluation 2 - Evaluation 3 & $\begin{array}{c}-139.45 \\
95 \% \text { Cl }(-249.76,-29.13)\end{array}$ & -0.28 \\
\hline Evaluation 3 - Evaluation 4 & $\begin{array}{c}-2.75 \\
95 \% \text { Cl }(-150.53,145.03)\end{array}$ & -0.005 \\
\hline
\end{tabular}

95\% Cl: confidence interval. 
Neovascularization also seems to play an important role leading to good clinical results showed by the eccentric training ${ }^{19}$. It is known that SIS specifically involves the supraspinatus tendon and it has also been linked to apoptosis in this tendon ${ }^{4}$. Although it is beyond the scope of this study, we can suggest that the high forces produced eccentrically may have induced the beneficial tissue remodeling response on the supraspinatus tendon of the subjects leading to a better physical function status according to the DASH score.

The lack of studies on eccentric training in subjects with SIS is evident. One study performed with only 9 subjects investigated if painful eccentric training for shoulder abductors was effective in subjects with chronic shoulder pain due to SIS $^{11}$. All subjects were on a waiting list for surgery and had to perform painful eccentric training for the supraspinatus and deltoid muscles for 12 weeks, twice a day, 7 days a week. After 12 weeks of eccentric training, 5 out of 9 subjects were satisfied with the result of the treatment, according to the Constant score, and withdrew from the waiting list for surgical treatment. At 52-week follow-up, these same subjects were still satisfied. Despite the difference in methodology between the eccentric training performed in the current study and Jonsson's et al. ${ }^{11}$ study, the subjects of our study also presented improved physical function of the upper limbs. However, it is important to state that our participants were younger, had shorter duration of symptoms and no indication for surgery.

Another study ${ }^{12}$ has also used eccentric training of the rotator cuff for patients with SIS. In addition, scapular control was also incorporated in the program and it was effective to decrease pain an increase function in these subjects.

In the present study, the eccentric training was performed with an isokinetic equipment. However, clinical relevant eccentric exercises can also be incorporated in a treatment protocol for those without isokinetic treatment. The exercises can be easily done with dumbbells and elastic bands and tubings as performed in the previous studies on eccentric training ${ }^{11,12}$.

Although there are no homogeneous isokinetic protocols to evaluate all types of patients, the use of isokinetic evaluation of muscle performance can be a valuable tool to assess the effectiveness of rehabilitation protocols because it provides objective documentation of dynamic movements. Isokinetic testing has been demonstrated to be reliable and valid to assess the shoulder complex ${ }^{17}$. However, it should be considered that this kind of testing is not specific to a certain muscle ${ }^{25}$, it evaluates the performance of a muscle group in a determined movement.

Lombardi et al. ${ }^{30}$ assessed the effects of progressive resistance training on pain, function, quality of life and muscle strength in subjects with SIS. The training program was held 2 days/week for 8 weeks. The resistance was evaluated individually every 2 weeks. Flexion, extension, medial rotation, and lateral rotation of the shoulder were the exercises done considering the eccentric and concentric phases. Peak torque and total work were evaluated during concentric flexion, extension, abduction, adduction, medial rotation and lateral rotation of the shoulder at $60^{\circ} / \mathrm{s}$ and $180^{\circ} / \mathrm{s}$. The training was effective in reducing pain and improving function and quality of life. However, there was no improvement in muscle torque. This finding was explained due to the lack of specificity between the exercises performed and the isokinetic evaluation, and to the short training period. In our study, although there was no lack of specificity, only few improvements in muscle performance were found and of few clinical significance. As such, we can suggest that the time of training was short for these subjects. Maybe our participants needed a longer time of intervention to improve the isokinetic parameters and reach a better within-group effect. However, this hypothesis needs to be further tested. Another possibility for finding only few changes in muscle performance can be that the participants may not have worked on maximum effort during the training sessions although the investigator asked them to perform maximal strength in all contractions. Despite the muscle soreness referred by all participants until the third session, which may indicate that they have put maximal effort during the training sessions, we cannot be confident that they were indeed working at maximum effort.

Therapeutic exercises have previously been determined to have long-term benefits for subjects with SIS ${ }^{51,52}$. In this investigation, benefits were observed even 6 weeks after the intervention period. It should be considered that no change was demonstrated in the baseline period. In comparison to studies that showed that exercise intervention is more effective than no intervention or placebo in subjects with SIS ${ }^{7,51,53}$, we can hypothesize that the natural course does not account for the positive effects in the isokinetic muscle performance, pain and physical function presented by the participants of this study. It is worth to consider the chronicity of the participants' condition (average 2.83 years), which suggests unlikely spontaneous recovery for subjects within the 4-month period of this study. However, we should also consider that Hawthorne effects might have taken place where subjects improve or modify an aspect of their behavior being experimentally measured simply in response to the fact that they are being studied ${ }^{54}$.

One may also argue if the improvement observed in the present study is a result of learning effect as training and tests were performed in the isokinetic dynamometer. We do not believe that learning effect took place because only few significant differences occurred in the isokinetic parameters and of small effect size. It should also be stated 
that improvement was also found in the DASH score, which is not related to the isokinetic, with large and moderate within-group effect sizes.

Further investigations are necessary to evaluate the effects of eccentric training programs on the scapular and humeral kinematics and on muscle activity of the supraspinatus and deltoid. It would also be relevant to perform imaging evaluation before and after the period of intervention to verify if changes in the supraspinatus tendon occur. Eccentric training has high clinical relevance, as it seems to improve the quality of the tendon by making it stronger and inducing remodeling of the collagen. In addition, eccentric training is the type of exercises that allows faster gain in muscular mass and neural adaptation compared to other types of training ${ }^{18}$. Future studies should also include a control group and wider range of motion.

\section{Conclusions $: \because$.}

This study suggests that isokinetic eccentric training for shoulder abductors is efficient to improve pain and function of the upper limbs in subjects with SIS and should be considered in rehabilitation.

\section{Acknowledgments : : :}

The authors are deeply grateful to the volunteers who participated in this study and to the funding agencies $\mathrm{Co}$ ordenação de Aperfeiçoamento de Pessoal de Nivel Superior (CAPES) and Conselho Nacional de Desenvolvimento Científico e Tecnológico (CNPq).

\section{References $: \because$.}

1. van der Windt DA, Thomas E, Pope DP, de Winter AF, Macfarlane GJ, Bouter LM, etal. Occupational risk factors for shoulder pain: a systematic review. Occup Environ Med. 2000;57(7):433-42.

2. Neer CS 2nd. Anterior acromioplasty for the chronic impingement syndrome in the shoulder: a preliminary report. J Bone Joint Surg Am. 1972;54(1):41-50.

3. Burke WS, Vangsness CT, Powers CM. Strengthening the supraspinatus: a clinical and biomechanical review. Clin Orthop Relat Res. 2002;(402):292-8.

4. Tuoheti Y, Itoi E, Pradhan RL, Wakabayashi I, Takahashi S, Minagawa H, et al. Apoptosis in the supraspinatus tendon with stage II subacromial impingement. J Shoulder Elbow Surg. 2005;14(5):535-41.

5. Bang MD, Deyle GD. Comparison of supervised exercise with and without manual physical therapy for patients with shoulder impingement syndrome. J Orthop Sports Phys Ther. 2000;30(3):126-37.

6. Camargo PR, Haik MN, Ludewig PM, Filho RB, Mattiello-Rosa SMG, Salvini TF. Effects of strengthening and stretching exercises applied during working hours on pain and physical impairment in workers with subacromial impingement syndrome. Physiother Theory Pract. 2009;25(7):463-75.

7. Ludewig PM, Borstad JD. Effects of a home exercise programme on shoulder pain and functional status in construction workers. Occup Environ Med. 2003;60(11):841-9.

8. McClure PW, Bialker J, Neff N, Williams G, Karduna A. Shoulder function and 3-dimensional kinematics in people with shoulder impingement syndrome before and after a 6-week exercise program. Phys Ther. 2004:84(9):832-48.

9. Michener LA, Walsworth MK, Burnet EN. Effectiveness of rehabilitation for patients with subacromial impingement syndrome: a systematic review. J Hand Ther. 2004;17(2):152-64.

10. Kuhn JE. Exercise in the treatment of rotator cuff impingement: a systematic review and a synthesized evidence-based rehabilitation protocol. J Shoulder Elbow Surg. 2009;18(1):138-60.

11. Jonsson $\mathrm{P}$, Wahlström $\mathrm{P}$, Öhberg $\mathrm{L}$, Alfredson $\mathrm{H}$. Eccentric training in chronic painful impingement syndrome of the shoulder: results of a pilot study. Knee Surg Sports Traumatol Arthrosc. 2006;14(1):76-81.

12. Bernhardsson S, Klintberg IH, Wendt GK. Evaluation of an exercise concept focusing on eccentric strength training of the rotator cuff for patients with subacromial impingement syndrome. Clin Rehabil. 2011;25(1):69-78.

13. Alfredson $\mathrm{H}$, Pietilä $\mathrm{T}$, Jonsson P, Lorentzon R. Heavy-load eccentric calf muscle training for the treatment of chronic Achilles tendinosis. Am J Sports Med. 1998;26(3):360-6.

14. Jonsson P, Alfredson H. Superior results with eccentric compared to concentric quadriceps training in patients with jumper's knee: a prospective randomised study. Br J Sports Med. 2005;39(11):847-50

15. Svernlöv B, Adolfsson L. Non-operative treatment regime including eccentric training for lateral humeral epicondylalgia. Scan J Med Sci Sports. 2001;11(6):328-34.
16. Young MA, Cook JL, Purdam CR, Kiss ZS, Alfredson H. Eccentric decline squat protocol offers superior results at 12 months compared with traditional eccentric protocol for patellar tendinopathy in volleyball players. Br J Sports Med. 2005;39(2):102-5.

17. Anderson VB, Bialocerkowski A, Bennell KL. Test-retest reliability of glenohumeral internal and external rotation strength in chronic rotator cuff pathology. Physical Therapy in Sport. 2006;7:115-21.

18. LaStayo PC, Woolf JM, Lewek MD, Snyder-Mackler L, Reich T, Lindstedt SL. Eccentric muscle contractions: their contribution to injury, prevention, rehabilitation, and sport. J Orthop Sports Phys Ther. 2003;33(10):557-71

19. Öhberg $\mathrm{L}$, Alfredson $\mathrm{H}$. Effects on neovascularisation behind the good results with eccentric training in chronic mid-portion Achilles tendinosis? Knee Surg Sports Traumatol Arthrosc. 2004;12(5):465-70.

20. Hawkins RJ, Kennedy JC. Impingement syndrome in athletes. Am J Sports Med. 1980;8(3):151-8

21. Jobe FW, Moynes DR. Delineation of diagnostic criteria and a rehabilitation program for rotator cuff injuries. Am J Sports Med. 1982;10(6):336-9.

22. Caliş M, Akgün K, Birtane M, Karacan I, Caliş H, Tüzün F. Diagnostic values of clinical diagnostic tests in subacromial impingement syndrome. Ann Rheum Dis. 2000;59(1):44-7.

23. Gerber C, Hersche 0, Farron A. Isolated rupture of the subscapularis tendon. J Bone Joint Surg Am. 1996;78(7):1015-23.

24. Ardic F, Kahraman Y, Kacar M, Kahraman MC, Findikoglu G, Yorgancioglu ZR. Shoulder impingement syndrome: relationships between clinical, functional, and radiologic findings. Am J Phys Med Rehabil. 2006;85(1):53-60.

25. Camargo PR, Ávila MA, Asso NA, Salvini TF. Muscle performance during isokinetic concentric and eccentric abduction in subjects with subacromial impingement syndrome. Eur J App Physiol. 2010;109(3):389-95.

26. Neer CS 2nd, Foster CR. Inferior capsular shift for involuntary inferior and multidirectional instability of the shoulder. A preliminary report. J Bone Joint Surg Am. 1980;62(6):897-908.

27. Lo IK, Nonweiler B, Woolfrey M, Litchfield R, Kirkley A. An evaluation of the apprehension, relocation, and surprise tests for anterior shoulder instability. Am J Sports Med. 2004;32(2):301-7.

28. Rowe CR, Zarins B. Recurrent transient subluxation of the shoulder. J Bone Joint Surg Am. 1981;63(6):863-72.

29. Hudak PL, Amadio PC, Bombardier C. Development of an upper extremity outcome measure: the DASH (disabilities of the arm, shoulder and hand) [corrected]. The Upper Extremity Collaborative Group (UECG). Am J Ind Med. 1996;29(6):602-8.

30. Lombardi IJr, Magri AG, Fleury AM, Da Silva AC, Natour J. Progressive resistance training in patients with shoulder impingement syndrome: a randomized controlled trial. Arthritis Rheum. 2008:59(5):615-22. 
31. Gummesson C, Atroshi I, Ekdahl C. The disabilities of the arm, shoulder and hand (DASH) outcome questionnaire: Iongitudinal construct validity and measuring self-rated health change after surgery. BMC Musculoskelet Disord. 2003;4:11.

32. Orfale AG, Araújo PMP, Ferraz MB, Natour J. Translation into Brazilian Portuguese, cultural adaptation and evaluation of the reliability of the Disabilities of the Arm, Shoulder and Hand Questionnaire. Braz J Med Biol Res. 2005;38(2):293-302.

33. Camargo PR, Haik MN, Filho RB, Mattiello-Rosa SMG, Salvini TF. Bilateral deficits in muscle contraction parameters during shoulder scaption in patients with unilateral subacromial impingement syndrome. Isokinet Exerc Sci. 2008;16(2):93-9.

34. Hébert LJ, Moffet H, McFadyen BJ, Dionne CE. Scapular behavior in shoulder impingement syndrome. Arch Phys Med Rehabil. 2002;83(1):60-9.

35. Leroux JL, Codine P, Thomas E, Pocholle M, Mailhe D, Blotman F. Isokinetic evaluation of rotational strength in normal shoulders and shoulders with impingement syndrome. Clin Orthop Relat Res. 1994;(304):108-15.

36. Townsend $\mathrm{H}$, Jobe FW, Pink M, Perry J. Electromyographic analysis of the glenohumeral muscles during a baseball rehabilitation program. Am J Sports Med. 1991;19(3):264-72.

37. Michener LA, McClure PW, Karduna AR. Anatomical and biomechanical mechanisms of subacromial impingement syndrome. Clin Biomech (Bristol, Avon). 2003;18(5):369-79.

38. Ellenbecker TS, Davies GJ. The application of isokinetics in testing and rehabilitation of the shoulder complex. J Athl Train. 2000:35(3):338-50.

39. Bandholm T, Rasmussen L, Aagaard P, Jensen BR, Diederichsen L. Force steadiness, muscle activity, and maximal muscle strength in subjects with subacromial impingement syndrome. Muscle Nerve. 2006;34(5):631-9

40. Camargo PR, Avila MA, de Oliveira AB, Asso NA, Benze BG, Salvini TF. Shoulder abduction torque steadiness is preserved in subacromial impingement syndrome. Eur $\mathrm{J}$ Appl Physiol. 2009;106(3):381-7.

41. Erol 0, Ozçakar L, Celiker R. Shoulder rotator strength in patients with stage $1-$ II subacromial impingement: relationship to pain, disability, and quality of life. J Shoulder Elbow Surg. 2008;17(6):893-7.

42. Ludewig PM, Cook TM. Alterations in shoulder kinematics and associated muscle activity in people with symptoms of shoulder impingement. Phys Ther. 2000;80(3):276-91.
43. Phadke V, Camargo PR, Ludewig PM. Scapular and rotator cuff muscle activity during arm elevation: a review of normal function and alterations with shoulder impingement. Rev Bras Fisioter. 2009;13(1):1-9.

44. Reddy AS, Mohr KJ, Pink MM, Jobe FW. Electromyographic analysis of the deltoid and rotator cuff muscles in persons with subacromial impingement. J Shoulder Elbow Surg. 2000;9(6):519-23

45. Cohen J. Statistical power analysis for the behavioural sciences. Hillsdale: Lawrence Erlbaum Associates; 1988.

46. Morrison DS, Frogameni AD, Woodworth P. Non-operative treatment of subacromial impingement syndrome. J Bone Joint Surg. 1997;79(5):732-7.

47. Hortobágyi T, DeVita P. Favorable neuromuscular and cardiovascular responses to 7 days of exercise with an eccentric overload in elderly women. J Gerontol A Biol Sci Med Sci. 2000;55(8):B401-10

48. Lindstedt SL, LaStayo PC, Reich TE. When active muscles lengthen: properties and consequences of eccentric contractions. News Physiol Sci. 2001;16:256-61.

49. Proske U, Morgan DL. Muscle damage from eccentric exercise: mechanism, mechanical signs, adaptation and clinical applications. J Physiol. 2001;537(Pt 2):333-45.

50. Kannus P, Jozsa L, Natri A, Järvinen M. Effects of training, immobilization and remobilization on tendons. Scand J Med Sci Sports. 1997;7(2):67-71.

51. Brox Jl, Gjengedal E, Uppheim G, Bøhmer AS, Brevik Jl, Ljunggren AE, et al. Arthroscopic surgery versus supervised exercises in patients with rotator cuff disease (stage II impingement syndrome): a prospective, randomized, controlled study in 125 patients with a $21 / 2$-year followup. J Shoulder Elbow Surg. 1999;8(2):102-11.

52. Haahr JP, Andersen JH. Exercises may be as efficient as subacromial decompression in patients with subacromial stage II impingement: 4-8-years' follow-up in a prospective, randomized study. Scand J Rheumatol. 2006;35:224-8.

53. Faber E, Kuiper JI, Burdorf A, Miedema HS, Verhaar JA. Treatment of impingement syndrome: a systematic review of the effects on functional limitations and return to work. J Occup Rehabil. 2006;16(1):7-25

54. McCarney R, Warner J, lliffe S, van Haselen R, Griffin M, Fisher P. The Hawthorne effect: a randomised, controlled trial. BMC Med Res Methodol. 2007;7:30. 